\title{
Understanding synchronization and hyper-synchronization in the the septo-hippocampal system
}

\author{
Antonio Garcia-Hernandez ${ }^{1 *}$, Julio C Facelli ${ }^{1,2}$, Luis V Colom ${ }^{3,4}$ \\ From Nineteenth Annual Computational Neuroscience Meeting: CNS*2010 \\ San Antonio, TX, USA. 24-30 July 2010
}

Epilepsy is a brain disorder in which networks of neurons, after an initial physiological insult, regroup and communicate abnormally (neuronal hyper-synchronizayion) [1]. Temporal lobe epilepsy (TLE) is the most common form of human epilepsy with a unique pathophysiological process; hippocampal sclerosis is an epileptogenic lesion encountered in patients with epilepsy [2,3]. Several lines of evidence point to the hippocampal/parhippocampal structures as the fundamental areas in seizure generation in TLE [4]-[6]. Experimental evidence indicates that the septum has a critical influence in the hippocampus, including the generation of highly synchronized activity know as hippocampal theta rhythm [7-12] which is present in different mammalian species including rodents and humans $[13,14]$. Hippocampal activity and synchronization (e.g theta rhythm generation or seizures generation) depends on the firing properties and connections among the different septal and hippocampal neuronal populations involved in these processes.

The medial septum inhibits the appearance of hippocampal interictal spikes and seizures through theta rhythm generation [15]. Medial septal neurons increase their firing rates during chronic epilepsy, and GABAergic neurons from both medial and lateral septal regions are highly and selectively vulnerable to the epilepsy process $[15,16]$. The firing rates of lateral septal neurons are chronically decrease by epilepsy, and a subset of these neurons increase their firing rates before and during hippocampal interictal spikes; moreover, the discharges of these lateral septal neurons are well correlate to hippocampal interictal spikes. In contrast, discharges from medial septal neurons are not correlated with

\footnotetext{
* Correspondence: antonio.garcia@utah.edu

'Department of Biomedical Informatics, University of Utah, Salt Lake City, Utah 84112, USA
}

hippocampal interictal spikes [17]. The neuronal networks that are responsible to generate normal brain biorhythms (e.g. hippocampal theta rhythm) can be altered by physiological insults and generate aberrant synchronized activity as well (e.g. epileptic seizures). Indeed, abnormal neural network oscillations are associated with several disease states, including schizophrenia, Alzheimer's disease, and epilepsy [18].

Computational models are an effective tool to better understand the underlying brain dynamics exposed by the experimental findings derived from neurobiological research. These models may be used to generate hypotheses that can further be tested experimentally with the purpose of increasing our understanding of the dynamics of neuronal networks leading to brain disease (e.g. epilepsy) $[19,20]$. The purpose of this study is to understand the normal connectivity and functionality of the septo-hippocampal system, and how such connections and functions are altered by temporal lobe epilepsy. We propose to use computational models and simulations of the septo-hippocampal neuronal networks to answer these questions.

\footnotetext{
Acknowledgements

National Library of Medicine Training Grant: LM007124 NIGMS, Division of Minority Opportunities in Research (MORE): 1R25GM083755. National Institute of General Medical Sciences/National Institute of Neurological Disorders and Strokes: SC1N2063950.

\section{Author details}

'Department of Biomedical Informatics, University of Utah, Salt Lake City, Utah 84112, USA. ${ }^{2}$ Center for High Performance Computing, University of Utah, Salt Lake City, Utah 84112, USA. ${ }^{3}$ Department of Biological Sciences, University of Texas at Brownsville/Texas Southmost College, Brownsville, TX 78520, USA. ${ }^{4}$ The Center for Biomedical Studies, University of Texas at Brownsville/Texas Southmost College, Brownsville, TX 78520, USA.
}

Published: 20 July 2010 


\section{References}

1. Bragin $\mathrm{A}$, Wilson $\mathrm{CL}$, Engel IJ Jr:: Chronic epileptogenesis requires development of a network of pathologically interconnected neuron clusters: a hypothesis. Epilepsia 2000, 41(Suppl 6):S144-152.

2. Engel J Jr: Introduction to temporal lobe epilepsy. Epilepsy Res 1996, 26(1):141-150.

3. Bertram EH: Temporal lobe epilepsy: where do the seizures really begin? Epilepsy Behav 2009, 14(Suppl 1):32-37.

4. El-Hassar L, Esclapez M, Bernard C: Hyperexcitability of the CA1 hippocampal region during epileptogenesis. Epilepsia 2007, 48(Suppl 5):131-139.

doi:10.1186/1471-2202-11-S1-P124

Cite this article as: Garcia-Hernandez et al.: Understanding

synchronization and hyper-synchronization in the the

septo-hippocampal system. BMC Neuroscience 2010 11(Suppl 1):P124.

Submit your next manuscript to BioMed Central and take full advantage of:

- Convenient online submission

- Thorough peer review

- No space constraints or color figure charges

- Immediate publication on acceptance

- Inclusion in PubMed, CAS, Scopus and Google Scholar

- Research which is freely available for redistribution

Submit your manuscript at www.biomedcentral.com/submit 